\title{
An Era of AI-personation \& Self(ie) Surveillance
}

\author{
Chris Campanioni \\ The Graduate Center/CUNY - chriscampanioni@gmail.com
}

\begin{abstract}
Any discussion of the social invisibilities engendered by the Internet necessarily demands further questioning as to how visibility, as an increasing cultural norm, has produced new inequalities in real life. This contribution combines autoethnographic research, social media analysis, and data analytics with theoretical frameworks such as phenomenology and psychology to globally investigate our current culture of AI-catfishing, social media metrics, and metrics manipulation.

My paper raises questions about re-materializing digital divides and inequalities in the "offline world" through citing self-surveillance techniques and algorithmic biases to

show how we are both at the whim of these AI-inflected prejudices but also complicit in reproducing them, whether through government coercion or our own cultural norms and rules. I trace our relationship with music technology to outline a trajectory of sensory disconnect and co-produced community-a framework for understanding current cultural phenomena and the ethics of distributed data, privacy, and the rendering of our bodies as a new kind of transaction, and currency. The rise of fake news is re-contextualized within the widespread rise of fake users: the various impersonations of self even and especially through AI.
\end{abstract}

Keywords: Social media, AI, selfie, surveillance, facial recognition, celebrity

\section{Uma Época de Personalização pela IA \& Self(ie) Vigiliância}

\begin{abstract}
Sumário
Qualquer discussão sobre as invisibilidades sociais geradas pela Internet requer, necessariamente, mais estudos, sobre a forma como a visibilidade, enquanto norma cultural crescente, produziu novas desigualdades na vida real. Este artigo combina pesquisa auto-etnográfica, análise social dos media e análise de dados com áreas teóricas, tais como a fenomenologia e a psicologia, para investigar globalmente a

nossa cultura atual de $I A$ - catfishing, métricas de media social e manipulação de métricas. O meu artigo levanta questões sobre a re-materialização de divisões e desigualdades digitais no "mundo offline" através da referência a técnicas de autovigilância e vieses algorítmicos para mostrar que estamos à mercê desses preconceitos infligidos pela IA, mas também cúmplices na sua reprodução,
\end{abstract}


seja através da coerção governamental, seja através das nossas próprias normas e regras culturais. Descrevo a nossa relação com a tecnologia da música, de forma a delinear uma trajetória de desconexão sensorial e comunidade co-produzida - uma estrutura para entender os fenómenos culturais atuais e a ética dos dados distribuídos, a privacidade e a representação dos nossos corpos como um novo tipo de transação e moeda. A ascensão das notícias falsas é recontextualizada dentro do crescimento generalizado de falsos utilizadores: as várias imitações do eu, especialmente através da IA.

Palavras-chave: Media social, IA, selfie, vigilância, reconhecimento facial, fama

\section{Who are you?}

Every day waking up and being forced to ask the same thing. What is desire if not this burden? Your whole life on repeat with so many privileged witnesses to watch. I wasn't looking. Looking doesn't work. Not all the time or ever. So I wake up every morning and think about the long quick drift toward the Hudson on Atlantic, or at least I used to, when I lived here. When I lived there. Every morning and sometimes at night, accelerating toward the water so I can lose myself. The Hudson flickers, the park lights flicker, the speeding yellow taxis and black sedans and the other runners flicker and dance all around you and you care about this intensely, with no recognition except the recognition of being inside your flesh for a minute more. Looking out to look in.

In sanctity and solitude we find who we are in the dark as in the light, terrified and softened at the same time to know that when we're stripped away, we can be nothing too.

The truth is I remind you of yourself.

The first thing I can remember about working as a model was the comp card; the 8.5x5.5 piece of card stock was your calling card and passport. It took you places. It was not a proof of purchase so much as it was proof your image could be purchased, at a later date and hopefully, at an interesting location.

After taking Polaroids-on a rooftop in Chelsea or in a dilapidated office-the next step was to produce that proof of purchase. A comp card typically contains two pages: a cover page with full-size portrait and a second page with a selection of repre- 
sentative shots from the portfolio and basic measurements. Without one, you could hardly get through the door at most castings that weren't cattle-calls. But today, all you need to be a model is a Twitter or an Instagram.

In 2015, during a discussion with students in the "Writing Across Disciplines" course I teach at Pace University in New York City, one woman related an anecdote her friend, an aspiring model, mentioned about a visit to Wilhelmina. "How many friends do you have?" the booker asked the aspiring model. Shrugging, she responded, "Here, or on the Internet?"

The answer, according to my student, according to her friend, was a minimum of one thousand followers on Instagram, one thousand others on Twitter. That number has only risen in 2018, at a moment in which, through rampant metric manipulation, citizenship via social media requires one to pay to play. Meanwhile, without the ability-or capital-to potentially re-present themselves to thousands of others in the span of a second, people are denied the opportunity of representation. Agencies, just like the clients and designers that solicit them, are overvaluing social media status by equating likes with dollar signs and cultural capital with the real thing.

People have always paid to be seen; today, people are paying to seem like they are being seen. The perception takes precedence because after enough views, perception materializes into reality. The more popular we seem to be, the more popular we become. It's why two of the five most common hashtags on Twitter in 2016 were \#ff and \#teamfollowback. In a matter of moments, everybody's status has risen; and like everything else today, our "user engagement" is being counted too. For ten years, Klout, which will have shut its doors four days from this writing, had tasked its team of analysts with measuring each of your social media accounts to eventually pump out a magic number that corresponded with your online influence, on a 100-marker scale.

No one likes being reduced to a number, except when we are the ones counting ours every day, insistently and on demand. In 2012, Forbes named Salesforce the "Most Innovative Company in America." That same year, Salesforce required prospective employees to have a Klout score of at least 35, listing it in a job opening as a "desired skill." Are we, today, at the precipice of manufactured spending? What is the cost of living? And is there an algorithm I can acquire to make me feel more like myself?

When imitation and aggregation are the MO, the real thing and the rarest no longer qualifies as genius but just the opposite. Deviation becomes a rounding error. Deviance becomes grist for someone else's product placement. Coincidentally — or 
not - it's much harder to acquire one million followers on Twitter than it is to acquire one million dollars, even though you might have to spend a significant amount of money to pay for those followers. In 2014, 10.1 million North Americans (8.3 percent of the country's population) reported a net worth of at least one million dollars (Frank, 2015) while only 2,643 Twitter accounts in the world have at least one million followers ${ }^{1}$ as of this writing.

This, too, has its precedence in other eras, as well as other industries, namely celebrity and the birth of publicity that formed in its wake. The allure of the film star, for example, was built on the see-saw between knowledge and mystery, and the desire left by that lacunae is what fills pockets with actual dollar bills. If a celebrity didn't have a viable story line, publicity agents would simply make one up, staging deaths, even, or raising the same body from the ground, ${ }^{2}$ in order to capture the attention of the media, and eventually, an audience. Rita Hayworth's career, too, as Joshua Gamson reveals during an interview with veteran PR agent Henry Rogers, was launched on the announcement of a made-up award for "best-dressed off-screen actress in Hollywood" - a falsified distinction which produced a very real photoshoot that landed on the cover of Look magazine.

In our ageless experiment of identity, testing the question "Who are you?" over and over again might yield a satisfying result but one that's likely as tenuous as your old Klout score. We'd like to see ourselves everywhere and see ourselves in everything. Who are you if not me, or the person next to you as you read this; the Matryoshka doll that keeps shedding layers until the big reveal: only another digit on the data map. The flip side to our personal branding is reduction and repetition, a chamber orchestra's echo that is as hollow as the space it requires to proliferate. Follow me follow me follow me follow me follow me follow me-

To be a model and to be a writer, to be both, comes from the same base desire to manufacture a reality; to prove that fiction is also and forever a truth. Life has always afforded me a lesson in salvage and redemption. I live each moment as though I forget—or fail to admit—-that it will only ever happen once. I don't want to have it

1 As of May 25, 2018, according to Twitter Counter, an analytics service that provides Twitter statistics and refreshes in real-time.

2 As was the case with "The Biograph Girl," Florence Lawrence, who died in 1910, as reported in the March 12, 1910 edition of Moving Picture World, and a second time, in 1938. 
happen only once. I want to relive it, as readers can, as viewers can, over and over. But when everyone is misapprehended-and misapprehending themselves-via a coy angle and a cloying caption, we also begin to muddy our own reflective waters, confusing other people's perceptions and expectations for us with who we are; surrounded by depictions of ourselves that have been consciously or subconsciously amended in turn until our own understanding of ourselves becomes perverted too. We are no longer able to tell the difference between the fact and the fiction, the representation or its re-presentation. Who are you? I ask, again and again.

Perception and expectation, separately, together, is the closest way we can come to understanding why we ask the question in the first place. In 1977, psychologists Theodore H. Mita, Marshall Dermer, and Jeffrey Knight tested the "mere-exposure" hypothesis in their study, "Reversed Facial Images." Individuals will prefer a facial photograph that corresponds to their mirror image rather than to an actual picture of themselves, probably an attitude we all readily admit today. But Mita, Dermer, and Knight were also able to demonstrate why we find our mirror images more appealing. It has more to do with nature than science. We-and other species, too-develop a preference for a stimulus based solely on our repeated exposure to it. Exposure turns into familiarity, which develops into comfort and satisfaction. It's the reason why we're afraid of difference. It's why we prefer to invent, imagine, and re-frame our identities to correspond with similarities and semblances.

One of the reasons why the selfie is so popular-one million self-shot a day-is because it pretends to portray us at our most vulnerable; up close and between the eyes, looking at you the way we'd want to be looked at ourselves. A manufacturing of authenticity that furnishes a suggestion of intimacy. But what if we actually feel vulnerable as a result of it? The viewer, the subject. The means may have been manufactured, but if the emotion elicited is real, who cares?

It's always the social or emotional message embedded in the image or song or words or work of art that exhilarates us, not how it's produced. And as everyone knows, digital instruments, too, can result in a very physical pleasure, the way music made purely with machines can be sensuous and erotic to move to, our bodies gyrating the way nature intended-and computers permit. It's this interplay with technology that has always shaped us and continues to do so; who we are, and how we perceive ourselves within our community.

Video may or may not have killed the radio star but the radio definitely killedor rather, reassembled - the live performance, what people asked for and what 
they expected to hear. Sound was first recorded in 1878, freezing voices and capturing music, allowing it to be savored, to be studied. But the earliest recording devices couldn't accurately render certain sounds, like drums and bass. And jazz musicians in the early twentieth century who aspired to be like the artists they heard on the radio would imitate what they heard while composing their own music, perpetuating a generation of jazz bereft of many of its moving parts. The perception was contrary to the reality, just as we often think of recordings as faithful replications instead of a translation: real to reel. In actuality, recordings are as inaccurate as our own internal recording of reality, the subjective, idealized memories we preserve and revise with time and circumstance. It's the reason why we hate the sound of our voice when it's played back to us on an answering machine. Technology picks up what we hear of ourselves, more or less, but as a whole, we sound strange to our own ears.

And as radio became popular in the twentieth century and more songs found more audiences, voices preserved and disseminated from places we'd never heard of or been to, we became familiar with more songs, or rather, we became familiar with a certain version of more songs. As David Byrne points out in his auto-theoretical 2012 book, How Music Works, eventually live music, too, tried to imitate the sound of recordings, its radio replica, dumbing down the original for a recognizable counterfeit, the lie being passed around in service of some truth. We need not look to the Internet or even technology to see evidence of this in other aspects of our culture. During his celebrity research, Gamson shares a conversation with a director, who tells him and also us - about Robin Leach's trademark Lifestyles of the Rich and Famous shrill voice - a product of Dan Ackroyd's impersonations of Leach on Saturday Night Live: "Robin got so much publicity out of it that Robin started doing Dan Ackroyd doing Robin. And now that's how he is, all the time" (Gamson, 1994, p. 77).

How we recognize ourselves, the look in our eyes, the way we smile, the tone of our voice or the tilt of our hip, the angle from which all of this is captured, has more to do with everyone else, their version of our reality playing on a loop, and us recording it to play this back. The reality of the recording supplants the reality of the real thing; it's the everyday version of the Hollywood sci-fi dystopian plot point of clones replacing their originals; artificial intelligence replacing human intellect; the truth which conceals that there is none.

We always fill in the discrepancies, the blanks, the missing sounds or missing letters, as we do with the visual gaps between video frames clicking above us in the 
darkness of the cinema, or the living room. And what's left is our selves, fashioned and re-fashioned to fit someone else's idea of us, the one that replaces whatever was there originally. To be named. Oh, to be named. What a beautiful rite, the before and not knowing.

The truth is I remind you of yourself. Because you made me in your image.

Companies like Devumi, Social Envy, and DIY-Likes.com sell Twitter followers and retweets to celebrities, businesses, and anyone else who can foot the bill, collecting millions of real dollars with fabricated users: bots that resemble real people, a new form of social identity theft, which is as crowd-sourced as the term suggests, cooperative and later, co-opted. As the New York Times reported in the early days of 2018, as many as 48 million of Twitter's reported active users, which accounts for almost 15 percent of its total base, are fake: automated accounts meant to simulate actual people. Facebook, too, has admitted to hosting up to 60 million automated accounts among its global social media empire. And although bots like the potentially several following you right now may also do more than boost your social media metrics ranking-influencing audiences, shifting political debates, obscuring news events and launching others into view as "trending topics" or "recommended content"they are also, at present, completely legal. And why not? In an age of Post Internet capitalism, if beauty remains what is useful, what is useful is what is productive; what produces.

But today it is also necessary to acknowledge that if you aren't paying for the product, you are the product. Our browsing history is already tracked, profiled, shared and sold by online marketers. They're called data brokers (Boutin, 2016). They act as auctioneers and traders of data collected from our digital traces; all the movements we knowingly and unknowingly make. You are right now being auctioned, and you don't even know it, or how much you're worth. How much your data fetches on the market. In ancient Greece and Rome, the obligation to hold a funeral was so strict that in the absence of a body, law required a wax or wooden double to be burned in its place. Today our data doubles outlive us, without having to go through the fire. And we can be even more useful to companies in death than we ever have been in life.

But much more useful than us or our data doubles are the innumerable duplicates that have only superficially been made in our images-those fake bots that pad not 
only companies like Deyumi's pockets but also social media giants like Facebook and Twitter whose market growth is tied to the number of users who appear as discoverable data, an inflation premised on the fiction of transforming a single real Twitter user into hundreds of different bots; "each," the New York Times reports, "a minute variation on the original" (Confessore, Dance, Harris, \& Hansen, 2018, p. 3). As it has done with almost every natural human tendency, the Internet has monetized what previously existed only as wish fulfillment. We still want to play make-believe but we want to do it on our terms. In our increasingly museum-curated lives, aestheticized and anesthetized, precautious and predetermined, we want the real, minus something indefinable, so that it won't be real. Our online identities, too, bear this indelible mark of forgery - the copy so flawless it could never be original. Whatever way you cut it, we are the sum of these simulations. We are not just living through the era of fake news, but fake "people" - AI meant to mimic us in insidious or outlandish ways: the Internet's New Clothes.

Coincidentally, or not, Wilhelmina was among the several companies and celebrity figures named as a frequent purchaser of fake followers in the New York Times report. Nearly all of the celebrities, politicians, journalists, and brand ambassadors who responded to requests for comments in the same article readily acknowledged the "total scam" they were contributing to as a client to companies like Deyumi, yet all of them kept buying - a list of customers that includes other New York Times correspondents - many of them out of desperation to keep up the façade, a common emotional response, I believe, but one that is also particular to this current moment; a phenomenon that has, unlike so much else, actually been created by the Internet instead of merely magnified by it. What's one more lie in a culture of prefabricated interactions? And is it still a fib if everyone already knows everyone is in on it? Devumi, much like modeling and talent agencies which poach "discovered talent," doesn't even make its own product; its employees are tasked with purchasing bots wholesale from other companies who manufacture them. The legacy of the company might ultimately be realized in the coincidence of its own con job: ripped off by a copycat, a bot-selling company based in the Philippines, called DevumiBoost.

Yet there is one thing we know for certain, accountable to our own accumulating data: If you retweet a post shared by a fake account, the engagement is still real. 
When you adjust your screen we are each looking at the same passage from Edward Said's Orientalism, a point of departure which begs the question of what the future holds for the eradication of local tradition and myth, against Western totalization in a present that already includes so much Internet-curated cultural imperialism:

One aspect of the electronic, postmodern world is that there has been a reinforcement of the stereotypes by which the Orient is viewed. If the world has become immediately accessible to a Western citizen living in the electronic age, the Orient too has drawn nearer to him, and is now less a myth perhaps than a place criss-crossed by Western, especially American interests. (Said, 1978, pp. 26-27)

Said, speaking in 1978, seems to echo Maurice Merleau-Ponty's thoughts about the self-imposition of value brought by the gaze (Merleau-Ponty, 1968, pp. 8-10), but neither thinker had any way of knowing what our AI-enriched culture would look like, literally resemble; resembled in the image of its creators: white, mostly heteronormative males. If we continue to replace our human faculties with an artificial intelligence that can do everything for us without our asking, will we even remember that we ever had a choice? To ask, to speak.

The issue is not, I think, that there are more cameras than humans in the world. The issue is our use of them to map one another on a world stage; the voluntary submission of our faces to what's become the largest image database in the world. Surveillance, from the French sur + veiller to watch, from Old French veillier, from Latin vigilare, more at vigil. Sur which means up, over, above. But today's surveillance does not only occur "from above."

Today there are more than two billion users on Facebook, 83 million of which, in 2012, were fake (Kelly, 2012). Over 136,000 photos are uploaded every minute. We look at one another the way we'd like to be looked at, a co-operative and participatory surveillance in which nothing is asked of us except that we lend our eyes to the wholesale rendering of our bodies as data, a situation in which we are both the targets and the targeters of others, complicit with the very real violence beneath the metaphorical violence of new media, drone operators and those who inhabit only the simulation of death represented by the red dot on topographic representations of actual cities. 
Today China is developing its "Social Credit System" to rate the citizenship of its nearly one and a half billion citizens, licensing eight private companies to develop systems and algorithms for China's Citizen Scores. As the policy stated as early as 2014, in the $12^{\text {th }}$ Five-Year Plan, when the design first went into effect: "It will forge a public opinion environment where keeping trust is glorious. It will strengthen sincerity in government affairs, commercial sincerity, social sincerity and the construction of judicial credibility." The move toward security is not just a national one; it cuts across individual identity every day. And as Jacques Derrida makes clear in his "Archive Fever" (1995), if not for the threat of death, we would not have the need for archives; the compulsion to add to them. Even as I type this, even as you read this back, my phone is asking me to perform another backup. National interests converge with our innate sense of self, or fear of losing it, in our impulse for retrieval—and perhaps, even, the hope of reclaiming.

In July of 2017, Facebook shut down one of its AI systems after chatbots began speaking in a language of their own creation (Maney, 2017). A month later, BabyQ and XiaoBing were taken offline by state-sanctioned censors in China when both robots began bad-mouthing the Chinese Communist Party (Li \& Jourdan, 2017). Both examples offer stark contrasts but also singular visions for our future. Whether we end up at the whim of artificial intelligence, or only its creators, we have already lost our own autonomy in identity formation. We have already lost the distinction between who we are, and what the world has made us into. Or what versions of us the world has silenced.

A study released in 2017 by two Stanford researchers claimed that artificial intelligence could detect a person's sexual orientation, provoking, again, the question of employing predictive analytics for "evidence" of categories of human identity, particularly when only two categories are included, particularly when non-white persons are not. What does AI say about humanity, except that you only count if you're white; that you only count if you're gay or straight? Bias and discrimination have found new, more insidious avenues of proliferation through algorithms.

With no knowledge of a person and with only pixels as its source material, an algorithm can begin to detect patterns and start to reproduce representations of your face, pictures that were never actually taken, photos of yourself that never existed. Auto-complete. 
The expression "to save one's face" comes from the Chinese phrase "tiu lien" - to suffer such a public disgrace so as to be unable to show one's face in public; literally to lose one's face. Saving face means preserving dignity. Dignity means maintenance, a balancing between a person and a model, life and the norm - conformity, the play of always being in one's place. But today, the notion of facial recognition in China takes on another layer of performance because of the overwhelming cultural significance of the selfie. The craze for transforming lao bai xing ("just plain folks") into wang hong lian ("Internet-celebrity face") has turned a photo-editing app like Meitu into a cultural custom and its company, also named Meitu - "beautiful picture," in Chinese-into the largest Internet company on the Hong Kong stock exchange despite launching less than ten years ago.

On another Meitu app called BeautyPlus, users can select a beauty level from 1 to 7 before adding a filter, including one called "personality," an attempt to undo the fact that everyone who uses Meitu-a sample population which accounts for more than half the selfies uploaded on Chinese social media and six billion photos a monthends up looking more, or less, and more or less the same. And it isn't just Meitu's progression into social media and the Chinese lexicon that has changed the face of China, it's the fact that several users actually use the app to preview different facial structures and alterations, before they go under the knife in the real world, a move from manufacturing digital desire to materializing it in the physical. But it's also a move from taking ownership of your body to being owned by it, turning the diversity of the human face into a preset of conformity, in which one standard of beauty dictates the literal look of an entire generation.

In The New Yorker article, "China's Selfie Obsession," one woman describes destroying every picture she can find of herself before her surgeries began. "The beauty of photos taken before the digital age," she tells the writer, "is, if you destroy it, it's gone for good" (Fan, 2017). Yet China's fixation on photo recognition is a microcosm of our global obsession with being seen; with documenting the traces of today to be looked at later, and looked at whenever one wants, an intra festum adherence to the present through obsessive repetition and intentional self-surveillance. Like so much else, the Internet has ostensibly democratized fame, allowing for new experiences of the self and a new economic exchange tied to performance and appearance. If the sixteenth century allowed for a new era of the face - the widespread dissemination 
of faces ushered in through copper engraving and printing technologies - today we are a global nation of AI-personalization and impersonations, a disintegration of past and future in favor of the intense "ecstasy of communication"; a Baudrillardian present which is only possible without any frame of reference. And without any context or coordinate system, culture porously slides into self-awareness, dispersing and disappearing only to re-form on new sites, new stages of play.

What is it that we want but to continue operating as simultaneous actor-and-audience, but also and especially, director? What is it that we want except to diagram the performance from a perch we can control, meticulously crafted and curated? It is worth repeating an earlier statement: As it has done with almost every natural human tendency, the Internet has only monetized what previously existed only as wish fulfillment. Another way of saying this is by reminding ourselves that there has always been a profound narcissism in our gaze-a narcissism and imperialism that has nothing to do with the Internet but which is inherent. And moreover, the potential for power, ultimately, surfaces in the technique itself, the process of a self-directed pleasure.

Imagine walking out the door of your office or home; you look up from your phone to see a dozen strangers you know everything about. Facial recognition technology - like the three different companies Facebook acquired in the last six years (Face.com in 2012; Masquerade and FacioMetrics in 2016) - makes this hypothetical scenario a growing reality. Startling, if its purchase wasn't $\mathrm{p}(\mathrm{l})$ aying off our innate desire for safety, the self-surveillance we already employ every day on social media. The only difference, in an age of augmented reality, is that we'll no longer even need our phones. Public spaces will become even less diverse; people will become less comfortable with diversity. When the gaze arrests itself in algorithms, it no longer looks inward. We will also lose our capacity for nuance, cruising, the allure of the unknown. And around the corner, another corner. The uncanny valley of an intimacy that cuts off the moment we know everything: what is there left to ask of ourselves, or others? The celebration of urban anonymity which is the city will become more segregated, more compartmentalized. Less open, less fluid. Informing the anti-Muslim rhetoric behind the ban on burqas in Austria, France, Belgium, and most recently, Denmark (May 2018), is the popular idea that nobody should have their face covered in public; that turbid point of view: if I can't see you, I should fear you. 
Any discussion of the social invisibilities engendered by and through the Internet necessarily demands further questioning as to how visibility, as an increasing cultural norm, has produced new inequalities in real life. How we see and what we see is quickly being reframed. Post Internet culture yields a database of facts about us beyond our immediate curatorial control; a future in which we no longer can manage what others can see about us; a future in which we no longer have a canvas on which to create or reclaim a persona. After the decline of anonymity, we are literally face-toface with the abolishment of identity-performance, and its utopic potential. Living in a world of everyday facial recognition is the final stage, or break, in the dissolution of the boundaries between celebrities and us. When everyone around you knows who you are and what you do-what you did today down to the metadata-it is us who will be both celebrated and reviled, self-secure and utterly disconnected.

\section{REFERENCES}

Planning Outline for the Construction of a Social Credit System (2014-2020). (2014, June 14). China Copyright and Media. Retrieved from https://chinacopyrightandmedia.wordpress.com/2014/06/14/planning-outline-for-the-constructionof-a-social-credit-system-2014-2020/

Boutin, P. (2016, March 30). The Secretive World of Selling Data About You. Newsweek. Retrieved from https://www.newsweek.com/secretive-world-selling-dataabout-you-464789

Byrne, D. (2012). How Music Works. New York City, New York: Three Rivers Press.

Confessore, N., Dance, G., Harris, R., \& Hansen, M. (2018, January 28). Buying Online Influence From a Shadowy Market. New York Times, p. A3.

Derrida, J. (1995). Archive Fever: A Freudian Impression. Diacritics, 25(2), 9-63.

Fan, J. (2017, December 11). China's Selfie Obsession. The New Yorker. Retrieved from https://www.newyorker.com/magazine/2017/12/18/chinas-selfie-obsession 
Frank, R. (2015, March 10). More millionaires than ever living in the US. CNBC. Retrieved from https://www.cnbc.com/2015/03/09/more-millionaires-than-everare-living-in-the-us.html

Gamson, J. (1994). Claims to Fame: Celebrity in Contemporary America. Oakland, California: University of California Press.

Kelly, H. (2012, August 3). 83 million Facebook accounts are fakes and dupes. CNN. Retrieved from https://www.cnn.com/2012/08/02/tech/social-media/facebookfake-accounts/index.html

Levin, S. (2017, September 7). New AI can guess whether you're gay or straight from a photograph. The Guardian. Retrieved from https://www.theguardian.com/ technology/2017/sep/07/new-artificial-intelligence-can-tell-whether-youregay-or-straight-from-a-photograph

Li, P., \& Jourdan, A. (2017, August 4). Chinese chatbots apparently re-educated after political faux pas. Reuters. Retrieved from https://www.reuters.com/article/uschina-robots-idUSKBN1AK0G1

Maney, K. (2017, July 5). How Facebook's AI Bots Learned Their Own Language and How To Lie. Newsweek. Retrieved from http://www.newsweek.com/2017/08/18/ ai-facebook-artificial-intelligence-machine-learning-robots-robotics-646944. $\underline{\mathrm{html}}$

Merleau-Ponty, M. (1968). The Visible and the Invisible (A. Lingis, Trans.). Evanston, Illinois: Northwestern University Press.

Mita, T., Dermer, M., \& Knight, J. (1977). Reversed facial images and the mere-exposure hypothesis. Journal of Personality and Social Psychology, 35, (8), 597-601. doi: $\underline{10.1037 / 0022-3514.35 .8 .597}$

Said, E. (1978). Orientalism. Abingdon-on-Thames, England: Routledge \& Kegan Paul. 